miento antirretrovírico de 1,12 a 4,51 meses, según la penetrancia. De acuerdo con los diversos cálculos de sensibilidad ensayados con el modelo, la proporción de eficacia por costo de las vacunas fue de \$89 900 por cada año de vida ajustado según la calidad (AVAC), recuperado. Aumentando la penetrancia a $50 \%$ se incrementó el beneficio proyectado de AVAC a 0,91 meses, con una proporción de eficacia según el costo de $\$ 45500$ por AVAC. En realidad se encontró que aun vacunas muy caras, de hasta \$10 000 la serie, pueden ser razonablemente eficaces en función del costo en países donde se gasta $\$ 100000$ por AVAC. Se concluyó que aun una vacuna levemente eficaz puede producir aumentos pequeños pero importantes de la esperanza de vida y constituir una opción viable frente al consumo de escasos recursos en la atención de personas con infección por VIH. (Walensky RP, et al. A therapeutic HIV vaccine: how good is good enough? Vaccine. 2004;22 (29-30):4044-4053.)

\section{Coinfección de Trypanosoma cruzi y virus de la inmunodeficiencia humana en hemofílicos}

A pesar de que los gobiernos de América Latina han tomado medidas para evitar la contaminación con agentes infecciosos en los bancos de sangre, todavía se dan problemas de salud asociados a la transfusión sanguínea, especialmente la infección por el virus de la inmunodeficiencia humana (VIH) y, en países endémicos, la enfermedad de Chagas. Los pacientes infectados antes de las acciones gubernamentales reflejan un problema médico continuo y los hemofílicos corren un riesgo más alto de infección que otras poblaciones debido a que deben recibir transfusiones con mayor frecuencia. La infección chagásica causada por el protozoo Trypanosoma cruzi afecta a cerca de 12 millones de personas y se transmite a los seres humanos principalmente por medio de la picada de insectos redúvidos infectados con tripomastigotos de T. cruzi. Sin embargo, la transmisión por transfusión de sangre todavía se produce en países como el Brasil.

La infección por T. cruzi suele ser asintomática, pese a la parasitemia y la parasitosis hística. La enfermedad llega a su estado crónico en solo $25 \%$ de los casos y a partir de su inicio pasan años antes de que puedan observarse sus manifestaciones clínicas. El corazón y el aparato digestivo son las partes más vulnerables del organismo. En modelos murinos, la administración de inmunosupresores estimula la parasitemia, lo que indica que un sistema inmunitario íntegro es esencial para mantener en equilibrio la relación entre el huésped y el parásito. Los estados clínicos que afectan al sistema inmunitario dejan a los pacientes chagásicos suscepti- bles de sufrir una reactivación de la infección por T. cruzi. En un número creciente de informes se describe a pacientes de sida con características clínicas poco comunes, tales como lesiones del sistema nervioso central y miocarditis, debidas a la reactivación de T. cruzi. En consecuencia, se ha propuesto que esas manifestaciones graves se empiecen a considerar como definidores del sida. Sin embargo, hay poca información sobre la asociación a largo plazo entre el VIH y T. cruzi. A continuación se resume un estudio del seguimiento clínico y de laboratorio de tres brasileños hemofílicos coinfectados con T. cruzi y VIH, que nunca tuvieron manifestaciones clínicas de reactivación de la infección por T. cruzi a pesar de su hiperparasitemia.

1) El primer paciente hemofílico descrito era un varón de 45 años, sin síntomas cardíacos o digestivos, diagnosticado de coinfección en 1985. En 1991 su estado se complicó con neumonía por Pneumocystis carinii y tuberculosis pulmonar, herpes zoster, candidiasis esofágica y criptococosis cerebral, y el paciente murió en 1997 de septicemia causada por Staphylococcus aureus resistente a la meticilina. Durante ese período se le administraron distintos tratamientos antirretrovíricos y su seguimiento nunca reveló ningún empeoramiento de la infección chagásica ni signos de alteraciones cardíacas o del sistema nervioso central.

2) En el segundo paciente, un varón de 29 años, se diagnosticó la coinfección en 1991. Mediante electrocardiograma se detectaron hemibloqueo ventricular derecho parcial y taquicardia sinusal, signos de miocardiopatía chagásica. La infección por VIH se intensificó hasta llegar al estadio CDC-A3 en 1997 con una viremia de $2,2 \times 10^{4} \mathrm{~m}$ copias/mL; pero el paciente rehusó los medicamentos antirretrovíricos. Durante siete años de seguimiento no se observó ninguna enfermedad definidora de sida, reactivación de T. cruzi ni empeoramiento de la miocardiopatía.

3) En 1975, se diagnosticó la enfermedad de Chagas en el tercer paciente - también varón, de 49 años- y en 1986 la infección por VIH, estadio CDC-A1. En 1994 se verificó un hemibloqueo ventricular derecho, posiblemente relacionado con la enfermedad de Chagas. El paciente padecía hipertensión grave y murió en 1997 de hemorragia intracerebral. Nunca se le detectaron enfermedades indicadoras de sida ni signos clínicos de reactivación de la infección por T. cruzi.

Para diagnosticar la enfermedad de Chagas, los tres pacientes se sometieron a diversas pruebas: a) la detección de T. cruzi mediante examen microscópico directo de sangre venosa heparinizada y del líquido cefalorraquídeo, cuando se consideraba pertinente; b) xenodiagnóstico —natural e in vitrocon ninfas de Panstrongylus megistus y Triatoma infes- 
tans; c) hemocultivo; d) reacción en cadena de la polimerasa con sangre y líquido cefalorraquídeo, y e) determinación molecular de los parásitos mediante técnicas de inmunotransferencia en papel de filtro.

El parásito chagásico se aisló de la sangre periférica de los tres pacientes descritos. Por xenodiagnóstico natural se obtuvieron porcentajes de ninfas positivas de 45,7; 51,3 y 30,7\% en los pacientes 1, 2 y 3 , respectivamente. Los hemocultivos fueron positivos en los pacientes 1 (20\% de los tubos) y 2 (60\% de los tubos). El xenodiagnóstico in vitro sirvió para evaluar periódicamente la parasitemia. Los pacientes 1 y 2 tuvieron los porcentajes más altos de ninfas positivas (21,2 y 39,2\%, respectivamente) al principio del estudio. En el paciente 1, el porcentaje disminuyó a $8 \%$ en 1996 y dio resultados negativos en 1997, poco antes de su muerte. El paciente 2 tuvo un porcentaje elevado de ninfas positivas durante todo el período de estudio, mientras que el paciente 3 tuvo una parasitemia de menos de 15\% hasta su muerte en 1997. Los exámenes microscópicos se llevaban a cabo por lo menos cuatro veces al año o cada vez que un paciente tenía síntomas que pudieran relacionarse con la reactivación de la enfermedad de Chagas. Nunca se vieron parásitos circulantes en las extensiones de sangre ni indicios de T. cruzi en exámenes microscópicos y cultivos del líquido cefalorraquídeo ni en la reacción en cadena de la polimerasa, aunque con esta última prueba se detectó ADNk de T. cruzi en la sangre periférica de todos los pacientes. Además, los exámenes citológicos y bioquímicos del líquido cefalorraquídeo no mostraron anormalidades, excepto en el paciente 1, que tuvo un resultado positivo a la prueba de antígenos criptococócicos.

Los linfocitos CD4+ disminuyeron durante el tiempo de estudio en los pacientes 1 y 2 , mientras que el paciente 3 mantuvo una concentración de linfocitos $\mathrm{T} \geq 500 / \mathrm{mm}^{3}$. Los recuentos de CD8+ se mantuvieron mayores de $500 / \mathrm{mm}^{3}$ en los tres pacientes.
Según los resultados indicados, la reactivación de infección por T. cruzi quizá no sea tan común como es de esperar en pacientes que también tienen sida. Sin embargo, se ha observado que la parasitemia es más alta en pacientes coinfectados que en chagásicos sin infección por VIH o sida debido, por lo menos en parte, al deterioro de la respuesta inmunitaria con linfocitos T. Actualmente, se cree que la reactivación de la infección por $T$. cruzi ocurre cuando el recuento de linfocitos $\mathrm{T}$ baja a menos de $200 / \mathrm{mm}^{3}$, si bien no se ha establecido una clara asociación entre el grado de parasitemia y el recuento de linfocitos CD4. Por otra parte, la persistencia de concentraciones normales de CD8 + apoya la teoría de que esas células tengan algo que ver con el control del parásito y que impidan la reactivación de la enfermedad.

Hasta ahora no se ha descrito la historia natural de la interacción entre T. cruzi y el VIH. El estudio descrito muestra que la infección por T. cruzi puede existir silenciosamente en pacientes con VIH, aunque tengan hiperparasitemia, baja respuesta específica de los linfocitos $\mathrm{T}$ y disminución de los CD4. La mayor parte de los informes señalan que la infección por $T$. cruzi se reactiva en presencia del sida, pero esto no ocurrió en el paciente 1, que tuvo muchas infecciones oportunistas. Quizá la explicación resida en el uso de azidovudina o medicamentos antimicóticos, que tienen algún efecto sobre $T$. cruzi y podrían reducir la parasitemia y prevenir la reactivación. De todos modos, parece claro que es preciso sospechar la presencia de infección por $T$. cruzi en cualquier persona infectado por el VIH que tenga una asociación epidemiológica a la enfermedad de Chagas. (Da-Cruz AM, Igreja RP, Dantas W, Junqueira ACV, Pacheco RS, Silva-Gonçalves AJ, et al. Long-term follow-up of co-infected HIV and Trypanosoma cruzi Brazilian patients. Trans R Soc Trop Med Hyg. 2004;98(12):728-733.) 